\title{
Mechanisms of Nuclear Suppression of Host Immunity by Effectors from the Arabidopsis Downy Mildew Pathogen Hyaloperonospora arabidopsidis (Hpa)
}

\author{
M.-C. Caillaud,${ }^{1}$ L. Wirthmueller ${ }^{2}$ G. Fabro, ${ }^{1,3}$ S.J.M. Piquerez,${ }^{1}$ S. Asai, ${ }^{1}$ \\ N. Ishaque, ${ }^{1}$ AND J.D.G. JONES ${ }^{1}$ \\ ${ }^{1}$ The Sainsbury Laboratory, John Innes Centre, Norwich Research Park, Norwich NR4 7UH, \\ United Kingdom \\ ${ }^{2}$ John Innes Centre, Norwich Research Park, Norwich NR4 7UH, United Kingdom \\ Correspondence: jonathan.jones@tsl.ac.uk
}

\begin{abstract}
Filamentous phytopathogens form sophisticated intracellular feeding structures called haustoria in plant cells. Pathogen effectors are likely to play a role in the establishment and maintenance of haustoria additional to their more characterized role of suppressing plant defense. Recent studies suggest that effectors may manipulate host transcription or other nuclear regulatory components for the benefit of pathogen development. However, the specific mechanisms by which these effectors promote susceptibility remain unclear. Of two recent screenings, we identified 15 nuclear-localized Hpa effectors (HaRxLs) that interact directly or indirectly with host nuclear components. When stably expressed in planta, nuclear HaRxLs cause diverse developmental phenotypes highlighting that nuclear effectors might interfere with fundamental plant regulatory mechanisms. Here, we report recent advances in understanding how a pathogen can manipulate nuclear processes in order to cause disease.
\end{abstract}

Plants are continuously exposed to microbial pathogen attacks but usually remain healthy because they are able to perceive microbes and then activate defense. In plants, a three-phase "zig-zag-zig" model explains much resistance and susceptibility to disease (Jones and Dangl 2006). All microbes trigger immune responses in plants via host-receptor-mediated recognition of pathogen-associated molecular patterns (PAMPs) (Nurnberger and Brunner 2002). Successful pathogens suppress or otherwise manipulate PAMP-triggered immunity (PTI) using effector molecules, which are predominantly small proteins secreted into hosts from pathogens, but may also include apoplastic effectors (Alfano and Collmer 2004). This "effector-triggered suppression" (ETS) of PTI is crucial to how pathogens overcome plant defense. Plants possess a further layer of defense in the form of resistance $(R)$ genes, the products of which directly or indirectly detect effectors (termed avirulence proteins, or AVRs), and upon recognition, further activate defense. Indirect detection by R proteins may occur via perception of effector-mediated alterations in host target proteins. R-protein-activated effector-triggered immunity (ETI) resembles PTI in that it results in a burst of reactive oxygen species, callose deposition, and defense gene induction, but it is more rapid and includes additional responses, such as programmed cell death during the socalled "hypersensitive response" (HR). Pathogen effector molecules that can either suppress host defenses or activate them if recognized by a Resistance $(\mathrm{R})$ protein provide profound insights into plant/pathogen interactions and particularly into host defense mechanisms. In addition to suppression of basal resistance and PTI, pathogen infection can lead to developmental changes during compatible interactions with its host. Infected plants with insect-transmitted phytopathogenic phytoplasma bacteria show severe symptoms, including leafy flowers (MacLean et al. 2011). Hyaloperonospora arabidopsidis (Hpa)-infected plants show curving of the leaves (Fig. 1) and early flowering (Korves and Bergelson 2003). Interestingly, in response to different plant pathogens, a similar developmental phenotype can be observed. Plant parasitic nematodes as well as Xanthomonas provoke plant cell hyperplasia and hypertrophy (Caillaud et al. 2008; Kay and Bonas 2009). In response to Pst, Xanthomonas, and Hpa, plants reduce time to flower and the number of aerial branches on the primary inflorescence (Korves and Bergelson 2003). These changes are prevented in a resistant plant, such as one carrying RPS2 (Korves and Bergelson 2003).

Plant pathogenic gram-negative bacteria use a specialized type III secretion system to deliver effectors inside host cells where they interact with target proteins involved in immunity (Abramovitch et al. 2003; Alfano and Collmer 2004). Functional characterization of bacterial effectors has provided unparalleled insights into the evolution of bacterial pathogenesis and the mechanisms used by bacterial proteins to interfere with host signaling and signal transduction processes. In contrast to bacterial plant pathogens, we know little about oomycete effector functions and their host targets. Eukaryotic plant pathogens such as rust and mildew fungi, and oomycetes including white rusts, downy mildews, and a subset of Phytophthora

\footnotetext{
${ }^{3}$ Present address: CIQUIBIC-CONICET, Departamento de Quimica Biologica, Facultad de Ciencias Quimicas, Universidad Nacional de Cordoba, Cordoba X500HUA, Argentina.

Copyright (C) 2012 Cold Spring Harbor Laboratory Press; all rights reserved; doi: 10.1101/sqb.2012.77.015115
}

Cold Spring Harbor Symposia on Quantitative Biology, Volume LXXVII 


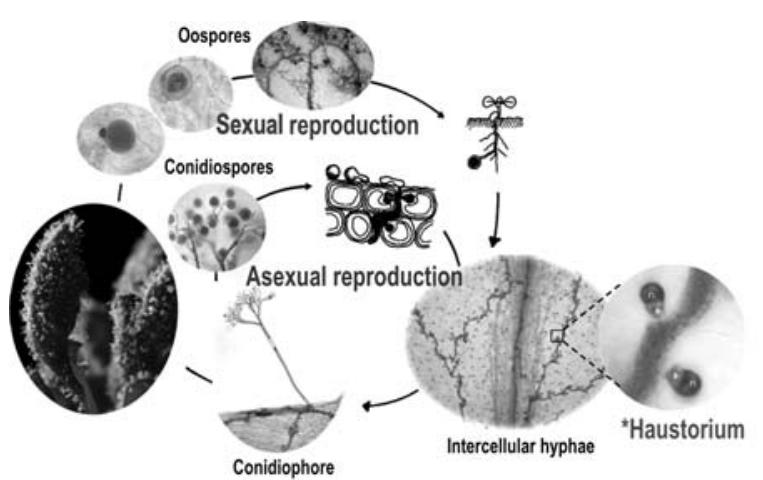

Figure 1. Schematic overview of the life cycle of Hyaloperonospora arabidopsidis on Arabidopsis thaliana (modified from Koch and Slusarenko 1990). Infections arise initially from oospores germinating on a root or conidiospores germinating on a leaf. Plants are colonized by mycelium growing intercellularly. Hyphae project haustoria into host cells. After a variable period of growth, conidiophores bearing conidiospores grow out of stomata. On germination, conidia initiate new rounds of infection. Oospores are formed concurrently with asexual spores. $\mathrm{Hpa}$-infected plant tissues were stained with trypan blue to highlight $\mathrm{Hpa}$ structures throughout the life cycle. Components of this diagram are not drawn to scale.

species, form specialized feeding structures called haustoria (Fig. 1). Haustoria are completely surrounded by invagination of the plant cell membrane and the nutrients required for oomycete growth must thus pass the plant membrane before being taken up by the pathogen (Fig. 1) (Ellis et al. 2006; Voegele and Mendgen 2011).

Given the sophisticated nature of these feeding structures, it is likely that pathogen effectors are translocated into the host cell in order to target plant proteins that are necessary for the establishment and maintenance of haustoria, for nutrient export, and for establishing the infection site as a metabolic sink (Birch et al. 2006; Ellis et al. 2006). The effectors are presumed to be first secreted by the oomycete haustoria and then taken up by the host cell through endocytosis in a process dependent on an aminoterminal RxLR uptake motif (Morgan and Kamoun 2007; Birch et al. 2009; Kale et al. 2010).

Hpa is a eukaryotic pathogen of Arabidopsis and has become a widely adopted model pathogen (along with Pseudomonas syringae [Pst]) for studies of Arabidopsis defense networks. Arabidopsis/Hpa interaction studies led to the identification of many Arabidopsis $R$ genes (resistance to Peronospora parasitica, former name of Hpa, RPP) (Slusarenko and Schlaich 2003). Conversely, identification of Hpa-recognized products (Arabidopsis thaliana recognized, or ATRs) was more recently achieved (ATR1, ATR13, ATR5, and ATR39) (Slusarenko and Schlaich 2003; Allen et al. 2004; Bailey et al. 2011; Goritschnig et al. 2011). Avirulent effectors from Phytophthora species have also been cloned (Shan et al. 2004; Armstrong et al. 2005; Tian et al. 2007; Dong et al. 2009; Oh et al. 2009). This finding coincides with the sequencing of several oomycete genomes (including $\mathrm{Hpa}$ ) and has allowed the prediction of a large number of effector gene candidates that share a conserved RxLR-host-targeting signal with the four known effectors (Win et al. 2007;
Baxter et al. 2010). This analysis revealed 134 "highconfidence" RxLR effector candidates (HaRxLs) - significantly fewer than in the Phytophthora infestans genome - providing a platform to investigate their function(s). Additional conserved WY-domain-secreted proteins can been found in $\sim 44 \%$ of RxLR effectors in Phytophthora spp. and 26\% in Hpa (Jiang et al. 2008; Boutemy et al. 2011). This domain constitutes a conserved $\alpha$-helical fold present in P. infestans Avr3a11, Avr3a4, and PexRD2 and Hpa ATR1 effectors (Boutemy et al. 2011; Chou et al. 2011; Yaeno et al. 2011) but not in the Hpa ATR13 effector (Leonelli et al. 2011). However, most of the predicted RxLR effectors have no homology with other known proteins, which makes their characterization a challenging process (Kamoun 2007).

Genome sequencing has revealed that a number of obligate pathogens have impaired nitrogen and sulphur assimilation pathways (Kemen and Jones 2012), from which we conclude that obligate pathogenic function includes manipulation of host metabolic function and transport of host metabolites. Little is known about biotrophic effector functions, mainly because working with obligate pathogens is difficult. This difficulty drove researchers to develop heterologous systems to indirectly assess effector functions (Sohn et al. 2007; Rentel et al. 2008; Schornack et al. 2010). Recognition of the avirulent effector by the corresponding $R$ gene generally initiates a localized celldeath response and should, therefore, be amenable for investigation in a cobombardment assay. This approach was previously used to characterize ATR1, ATR13, and ATR5 (Allen et al. 2004; Rehmany et al. 2005; Bailey et al. 2011). However, the tedious amount of work required and the variability of the results has thus far prevented screening of candidate effector libraries using this approach.

The effector detector vector (EDV) system is based on the delivery by the bacterial T3SS of Pst of an effector of interest fused to the amino-terminal part of the bacterial effector AvrRPS4 (Sohn et al. 2007). Using this EDV system, Sohn et al. (2007) have shown that Hpa effectors ATR1 and ATR13 confer enhanced virulence to the bacterial pathogen Pst DC3000. Kemen et al. (2011) showed with this method that several classes of Albugo laibachii effectors conferred enhanced virulence to Pst DC3000. In parallel, a collection of "HaRxL-EDV" from Hpa Emoy2 was screened for bacterial virulence on several Arabidopsis accessions (Table 1). We observed that variable HaRxLs, such as ATR1 and ATR13, performed differently on selected Arabidopsis accessions, whereas conserved "core" HaRxLs, such as HaRxL62, enhance plant susceptibility to Pst in all of the Arabidopsis accessions (Fabro et al. 2011). Taking advantage of the HaRxL collection created by Fabro et al. (2011), we designed a fluorescence-imaging-based screen in planta to assess their subcellular localization. We observed that a large majority $(66 \%)$ of HaRxLs targeted the plant cell nucleus. Of the $16 \mathrm{HaRxLs}$ that localized exclusively to the plant cell nucleus (Fig. 2), 11 targeted the nucleolus, including ATR13 ${ }^{\text {Emoy2 }}$ (Caillaud et al. 2012).

An important role in plant defense has been attributed to nuclear dynamics, because a growing number of reports 
Table 1. Characteristics of the nuclear-HaRxLs

\begin{tabular}{|c|c|c|c|c|c|c|c|c|c|c|c|}
\hline \multirow[b]{2}{*}{ Names } & \multirow[b]{2}{*}{ WY motif } & \multirow[b]{2}{*}{ Polymorphism } & \multirow[b]{2}{*}{ Expression } & \multicolumn{5}{|c|}{ EDV } & \multicolumn{3}{|c|}{ Arabidopsis-stable lines expressing single $\mathrm{HaRxL}$} \\
\hline & & & & $(+)$ & $(=)$ & $(-)$ & $\begin{array}{c}\text { Callose } \\
\text { suppresion }\end{array}$ & $\begin{array}{l}\text { Turnip } \\
\text { assay }\end{array}$ & $\begin{array}{l}\text { Developmental } \\
\text { phenotype }\end{array}$ & PTI suppression & Pathogen assays \\
\hline ATR13 & - & HIGH (28) & $\mathrm{B}, \mathrm{D}$ & 8 & 1 & 3 & yes + & $(=)$ & - & $\begin{array}{l}\text { yes (ROS); yes } \\
\text { (callose) }\end{array}$ & enhances $H p a+P s t$ growth \\
\hline HaRxL2 & yes & NO $(0)$ & $\mathrm{C}$ & - & - & - & - & - & twisted organs & - & enhances $H p a$ growth \\
\hline HaRxL18 & yes & LOW (2) & $\mathrm{A}, \mathrm{B}, \mathrm{C}$ & 0 & 7 & 5 & no & $(=)$ & - & - & - \\
\hline HaRxL24 & yes & LOW (3) & $\mathrm{A}, \mathrm{B}, \mathrm{C}$ & - & 4 & no & - & $(=)$ & - & - & - \\
\hline HaRxL36 & - & LOW (4) & A,C & 0 & 8 & 4 & no & $(=)$ & $\begin{array}{l}\text { defect in apical } \\
\text { dominance }\end{array}$ & - & - \\
\hline HaRxL44 & - & LOW $(2)^{*}$ & $\mathrm{~B}, \mathrm{C}, \mathrm{D}$ & 6 & 4 & 2 & yes + & $(=)$ & wavy leaves & $\begin{array}{l}\text { yes (ROS); yes } \\
\text { (callose) }\end{array}$ & enhances $H p a+P s t$ growth \\
\hline HaRxL45a & - & MEDIUM (11) & $\mathrm{A}, \mathrm{B}, \mathrm{C}$ & 6 & 3 & 3 & yes & $(+)$ & & $\begin{array}{l}\text { yes (ROS); yes } \\
\text { (callose) }\end{array}$ & enhances $H p a+P s t$ growth \\
\hline HaRxL68 & - & LOW (2) & $\mathrm{C}$ & 4 & 8 & 0 & yes & $(+)$ & - & - & - \\
\hline HaRxL70 & - & - & - & - & - & - & - & - & $\begin{array}{l}\text { defect in apical } \\
\text { dominance }\end{array}$ & - & - \\
\hline HaRxL73 & - & HIGH (34) & $\mathrm{A}, \mathrm{B}, \mathrm{C}$ & 9 & 3 & 0 & yes & $(=)$ & pale green leaves & - & - \\
\hline HaRxL89 & - & LOW (5) & $\mathrm{A}, \mathrm{B}, \mathrm{C}$ & 3 & 7 & 2 & no & $(-)$ & & $\begin{array}{l}\text { yes (Pf0-1); yes } \\
\text { (callose) }\end{array}$ & - \\
\hline HaRxL106 & yes & HIGH (23) & $\mathrm{B}, \mathrm{C}$ & 9 & 1 & 2 & yes & $(+)$ & etiolated leaves & $\begin{array}{l}\text { yes (ROS); yes } \\
\text { (callose) }\end{array}$ & enhances $H p a+P s t$ growth \\
\hline HaRxLL3a & probably yes & multigene family & - & 4 & 8 & 0 & no & $(=)$ & curly leaves & - & - \\
\hline HaRxLL60 & - & LOW (5) & $\mathrm{A}, \mathrm{B}, \mathrm{C}$ & 5 & 7 & 0 & no & $(=)$ & bushy & $\begin{array}{l}\text { yes (ROS); no } \\
\quad \text { (callose) }\end{array}$ & enhances $P s t+$ decreases $H p a$ growth \\
\hline HaRxLL108 & - & LOW (3) & $\mathrm{B}, \mathrm{C}$ & 6 & 4 & 2 & yes+ & $(+)$ & - & - & - \\
\hline HaRxLL470b & - & LOW (2) & $\mathrm{A}, \mathrm{C}$ & 1 & 5 & 6 & no & $(-)$ & - & - & - \\
\hline
\end{tabular}

Presence of the WY motif is presented. (Polymorphism) Number of polymorphic amino-acid positions indicated in brackets, (expression data) A, Sanger ESTs generated from Hpa Emoy2 conidiospores; B, 454 ESTs (embryonic stem cells) generated from $H p a$-infected tissue ( 3 dpi); C, Illumina GA2 reads from Hpa-infected tissue ( 3 and $7 \mathrm{dpi}$ ); D, RT-PCR done on Hpa-infected tissues. Subcellular-localization of GFP/RFP (red fluorescent protein)-tagged HaRxLs; (EDV) Pst-LUX HaRxLs-EDV tested in 12 Arabidopsis accessions; $(+)$ enhanced bacterial growth; $(-)$ decreased bacterial growth; $(=)$ same bacterial growth as control. (Callose suppression) Pst DC3000 $\Delta$ CEL pEDV-HaRxLs tested for suppression of callose triggered by $\Delta$ CEL mutation in plants: (yes+) high suppression; (yes) suppression; (no) no suppression. (Turnip assay) Pst DC3000 LUX pEDV-HaRxLs tested for enhanced growth (+); decreased growth ( - ) or same growth as control (=) in Brassica rapa cv (just right). Arabidopsis-stable lines expressing single HaRxLs (developmental phenotype observed); tested for PTI suppression phenotype (ROS, callose, or HR) and differential pathogen growth (Pst or Hpa). ( $($ ) Not determined. References: (1) Fabro et al. (2011), (2) Caillaud et al. (2012), (3) Badel et al. (unpub), (4) Rehmany et al. (2005). 

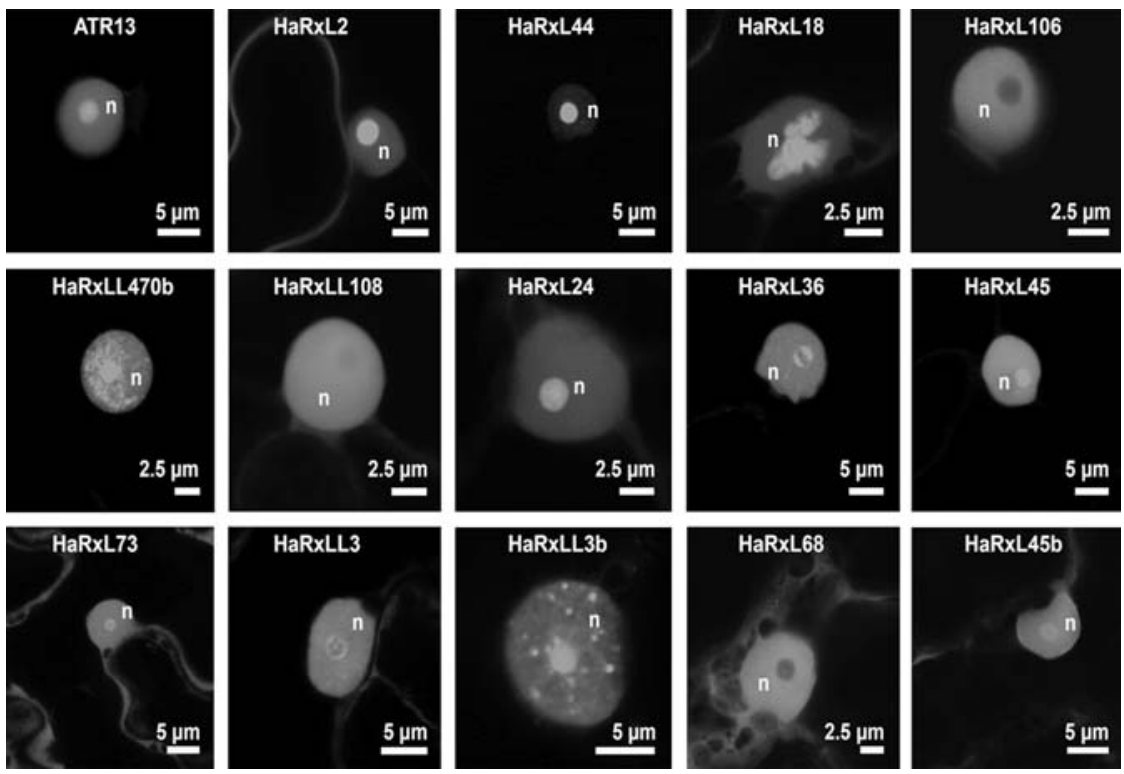

Figure 2. HaRxLs localize to the plant host nucleus. GFP (green fluorescent protein)-tagged HaRxLs were transiently expressed in Nicotiana benthamiana and analyzed by confocal microscopy. From Caillaud et al. (2012).

revealed that nuclear localization of pathogen effectors, $\mathrm{R}$ proteins, and key host components, including transcription factors (TFs) and regulators, is essential for plant immunity (Deslandes and Rivas 2012). Recent studies also show the importance of nucleocytoplasmic trafficking during plant innate immunity (Deslandes and Rivas 2012). The immune regulators NPR1, EDS1, and PAD4, as well as several $\mathrm{R}$ proteins and their bacterial cognate effectors, show dynamic, quantitative, and temporal changes in subcellular localization that are key to the modulation of their activity during defense signaling (Wirthmueller et al. 2007; Kwon et al. 2009; Bhattacharjee et al. 2011; Heidrich et al. 2011; Zhu et al. 2011; Bai et al. 2012). However, the signaling mechanisms and processes that lead to changes in protein subcellular localization and activity are still to be unraveled. Importantly, a significant number of effector proteins are transported to the nucleus via the host nuclear import machinery (Marois et al. 2002; Bai et al. 2009; Canonne et al. 2011; Canonne and Rivas 2012; Rivas 2012). This observation suggests that effectors may manipulate host transcription or other nuclear regulatory components for the benefit of the pathogen. Here, we report recent advances in understanding how effectors manipulate nuclear host immunity in order to promote virulence.

\section{NUCLEAR-HaRxLs GIVE VARIOUS DEVELOPMENTAL PHENOTYPES WHEN EXPRESSED IN PLANTA}

Transient expression can be used to assess the effect of the ectopic expression of a given effector in planta (Marois et al. 2002; Armstrong et al. 2005; Dong et al. 2011) but can lead, however, to complications such as unequal and nonsynchronized effector expression and the presence of Agrobacteria in the plant tissues. For this reason, we analyzed stable effector expression in planta, particularly for studying Arabidopsis-compatible pathosystems. Stable effector expression in planta allows us to test whether the ectopic expression of a given effector affects plant susceptibility toward the corresponding pathogen (Bozkurt et al. 2011; Fabro et al. 2011; Caillaud et al. 2012) or even other pathogens (van Esse et al. 2008; Hewezi et al. 2010; Bouwmeester et al. 2011; Fabro et al. 2011). Using this approach, effectors from Hpa, including ATR13, were shown to suppress plant defenses, notably PAMP-induced ROS burst and callose deposition, which are typical indicators of plant immune response activation (Sohn et al. 2007; Fabro et al. 2011).

Expression in planta of one single effector can phenocopy plant developmental changes observed during the corresponding compatible infection. Ectopic expression of the TAL effector AvrBs3 induces hypertrophy of mesophyll cells in susceptible plants that resembles the symptoms induced during infection with Xanthomonas (Buttner and Bonas 2002; Marois et al. 2002; Kay et al. 2007). SAP54 from the Aster Yellows phytoplasma strain Witches' Broom (AY-WB) alters floral development, resulting in the production of leaf-like flowers that are similar to those produced by infected plants (Sugio et al. 2011). Pathogens can also secrete effectors that mimic host plant proteins in order to promote virulence. For example, plant-parasitic cyst nematodes secrete GrCLE effectors in order to modify selected host cells into multinucleate feeding sites (Mitchum et al. 2008). CLE genes encode secreted peptides that function in the extracellular space as intercellular signaling molecules and bind to cellular surface receptor-like proteins to transmit a signal. GrCLE1 binds directly to plant CLE receptors 

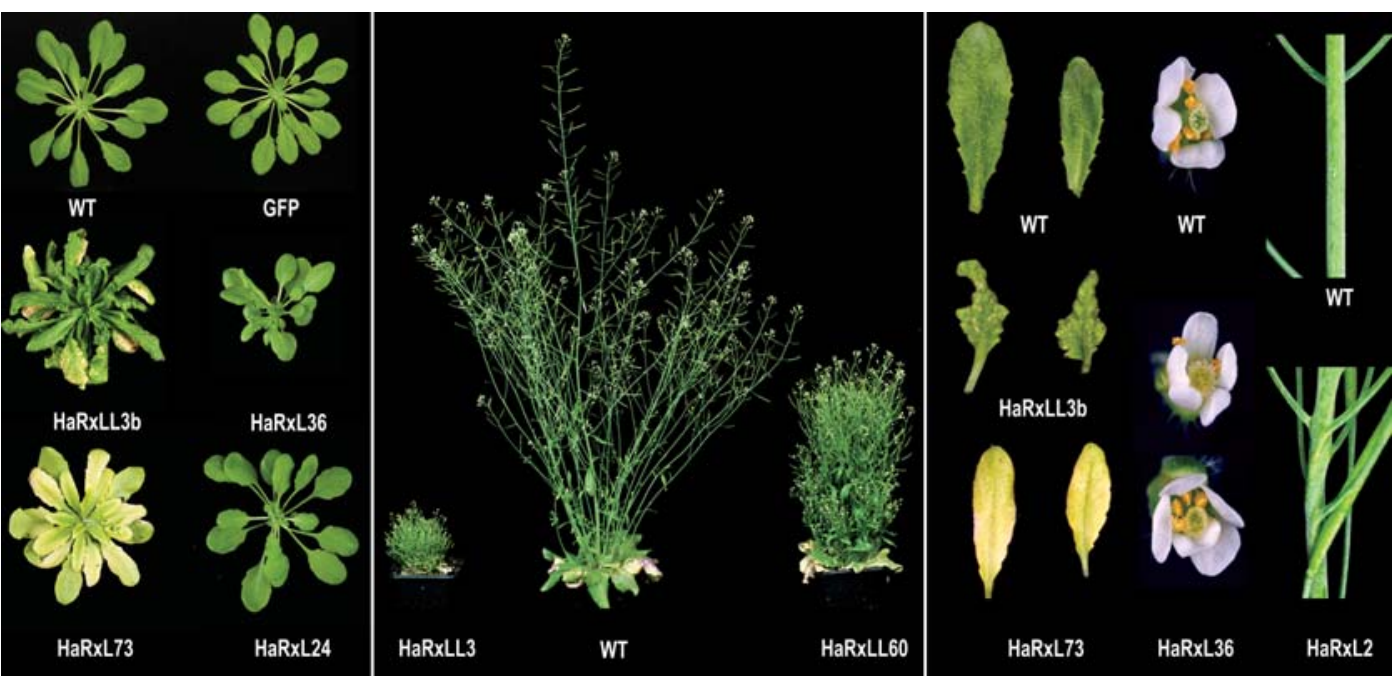

Figure 3. Nuclear-HaRxLs expression in planta leads to diverse morphological phenotypes. (Left to right) Macrophenotype of Arabidopsis lines expressing tagged (or untagged) version of the nuclear HaRxLs under the control of the $35 \mathrm{~S}$ promoter. The wildtype (WT) plant and the plant expressing GFP alone (GFP) are indicated. HaRxLL3b expression in planta enhances leave curvature. HaRxL36 expression in planta results in an abnormal number of leaves. HaRxL73 induces early flowering compared with the WT plant. HaRxL24 expression in Arabidopsis leads to the formation of two shoot apical meristems instead of one, in all plants. HaRxLL3 and HaRxLL60 plants are bushy. Shown is the phenotype in diverse plant organs of Arabidopsis lines expressing the tagged version of nuclear HaRxLs under the control of the $35 \mathrm{~S}$ promoter. HaRxLL3b induces curvy leaves when stably expressed in planta, whereas HaRxL73 expression results in albino leaves. HaRxL36 expression induces frequent five-petal flowers instead of four-petal flowers observed in WT plants. HaRxL2 expression in planta leads to a twist of the organs in the entire aerial part of the plant, including the stem.

CLV2, BAM1, and BAM2 (Guo et al. 2011). Transgenic lines expressing GrCLE effectors phenocopy the wuschel mutant, characterized by premature termination of the shoot apical meristem and the development of flowers lacking the central gynoecium (Wang et al. 2005).

We generated transgenic lines that stably express nuclear-HaRxLs under the control of the $35 \mathrm{~S}$ promoter, with or without an epitope-tag (Fig. 3, Table 1). We often observed strong developmental phenotypes in 5-week old plants (Fig. 3). Nuclear-HaRxLs expressed in Arabidopsis often result in dwarf or early flowering plants (Fig. 3). Pleiotropic developmental phenotypes due to the ectopic expression of nuclear-HaRxLs are observed in different plant organs (Fig. 3). HaRxLL3b induced defects in leaf curvature whereas HaRxL73 expression leads to albino and early flowering plants. HaRxL106 and HaRxLL60 modify the shape of the leaves that become either elongated and darker or serrated and smaller, respectively (Fabro et al. 2011). HaRxL36 causes flowers with variable numbers of petals, whereas HaRxL2 provokes twisted plant organs (Fig. 3). These developmental phenotypes highlight the fact that nuclear effectors might interfere with fundamental plant regulatory mechanisms in order to promote pathogen virulence and indicate to us where to look to identify their functions.

\section{NUCLEAR-HaRxLs INTERACT WITH TRANSCRIPTIONAL REGULATORS}

During the last decade, a wealth of knowledge has emerged from studies on bacterial effectors. A central concept emerging from these studies is that the targets of effectors are key components of host defense, and by defining effector targets, we learn about plant defense mechanisms. Following delivery into the plant cell, microbial effectors may be targeted to different cellular compartments, where they can manipulate a variety of host cellular functions (see Win et al. 2012). In the case of nuclear-localized effectors, we might expect that they interact with proteins implicated in chromatin remodeling, DNA replication, DNA transcription, RNA processing, or messenger RNA (mRNA) (and protein) import/export. The yeast two-hybrid system ( $\mathrm{Y} 2 \mathrm{H})$ has been used to identify plant proteins that interact with effectors. For example, $P$. infestans AVR3a was shown to interact with the plant E3 ligase CMPG1 (Gilroy et al. 2011). In planta, Avr3a can stabilize the nucleolus-localized CMPG1, potentially preventing host cell death during the biotrophic phase of infection (Bos et al. 2010). The Ralstonia acearum effector PopP2 was used as bait in the screening of a Y2H Arabidopsis cDNA library generated from root tissues challenged with the $R$. solanacearum GMI1000 strain expressing PopP 2 (Bernoux et al. 2008). They identified the interaction between the Arabidopsis cysteineprotease RD19 and PopP2. After its coexpression with PopP2, RD19 relocalized to the plant nucleus probably to form a nuclear complex required for activation of plant defense (Bernoux et al. 2008). Y2H analyses identified a direct interaction between the root-knot nematode effector 16D10 and the plant transcription factor SCARECROW (Huang et al. 2006a) that may represent an early signaling event in the root-knot nematode-host interaction. A largescale $\mathrm{Y} 2 \mathrm{H}$ screen of $\mathrm{Hpa}$ and Pst effectors has been conducted through the development of an automated 


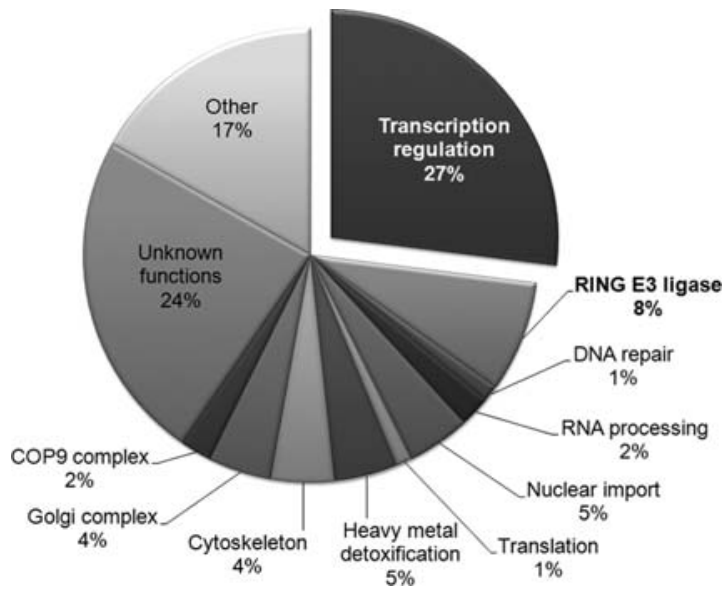

Figure 4. Nuclear-HaRxLs interact with Arabidopsis transcriptional regulators. Chart represents the predicted functions of nuclear-HaRxLs plant targets. Data extracted from Mukhtar et al. (2011).

Y2H system to test $\sim 8000$ Arabidopsis proteins (AtORFeome2.0) against 83 different effectors (Mukhtar et al. 2011). This led to the identification of 165 putative effector targets, some of which are considered hubs, as summarized in the PPIN1 database (Mukhtar et al. 2011).

Such large-scale experiments can prove extremely useful to guide the quest for knowledge of effector functions. By analyzing the results obtained in the Mukhtar et al. (2011) screening, we found that nuclear HaRxL interactors show an overrepresentation of transcriptional regulators (Fig. 4). In addition, each nuclear HaRxL tested interacts with at least one transcriptional regulator. As a part of the validation of this screening, we cloned several HaRxL-plant targets of either known or unknown function (Mukhtar et al. 2011). Transient expression of the GFP-tagged version of HaRxLs-plant targets revealed the abundance of nuclear-localized protein interacting with HaRxLs (Fig. 5A). Interestingly, some of the HaRxLs-plant-target subnuclear localization patterns resemble specific nuclear subcompartments (Fig. 5A). For example, At1G17970, which interacts with HaRxLL470b and HaRxL44, has a localization pattern that can be associated with plant spliceosomes (Fig. 5A) (Brown et al. 2005), whereas BOI, which interacts with ATR13 and HaRxL44, resembles the pattern obtained with RNA-dependent polymerase II (Fig. 5A) (Pedrotti et al. 2011). Thus, HaRxLs interact with key factors of the transcriptional/posttranscriptional plant machinery, presumably to promote virulence. Remarkably, nuclear HaRxLsplant targets interact with known factors implicated in plant immunity such as RLK, NB-LRR, or RIN4 (Fig. $5 \mathrm{~B}$ ), indicating that plant targets of HaRxLs might have an important role in the plant immune response.

\section{CONCLUSIONS}

Increasing evidence indicates that pathogen effectors can target a wide range of cell compartments in order to suppress host immunity, promote disease, and in some instances, modulate plant gene expression. Knowledge of effector functions of hemibiotrophic pathogens such as Pst and Phythophthora spp. has expanded considerably in recent years, but much less is known about effectors
A

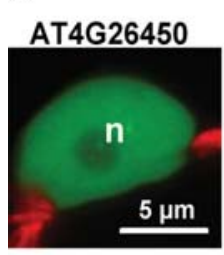

HUB1

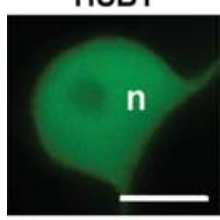

ASIL1

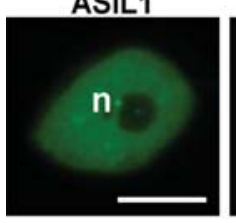

At5G27860

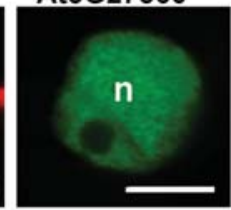

$\mathrm{BOI}$

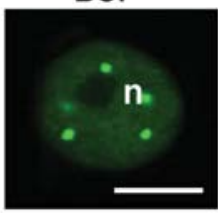

At1G17970

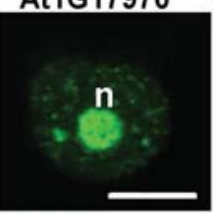

Figure 5. Nuclear-HaRxLs interact directly or indirectly with components of the nuclear plant immune system. $(A)$ Subcellular localization of several nuclear-HaRxL plant targets. GFP-tagged nuclear-HaRxL plant targets were cloned and transiently expressed in $N$. benthamiana and analyzed by confocal microscopy. (B) Network of interaction between nuclear-HaRxLs and their plant targets revealed that nuclear-HaRxLs interact directly or indirectly with nuclear components. Proteins (nodes) are color-coded; HaRxLs (purple), plant proteins including literature-curated defense proteins (blue), amino-terminal domains of NB-LRR immune receptors (red), and "immune interactors" (gray). (Black edges) Protein-protein interactions. Data extracted from Mukhtar et al. (2011). 
from biotrophic pathogens, mainly due to the difficulties of working with such biological systems. In contrast with hemibiotrophs (and necrotrophs), obligate plant pathogens might have developed a battery of effectors that act in the maintenance of the biotrophy, instead of actively causing necrosis. In fact, biotrophic parasitism is an extremely successful mode of life that resembles endosymbiosis. The function of effectors from biotrophs might thus include not only the active impairment of plant defense reactions but also the reprogramming of the plant cell in order to obtain nutrients during a relatively long biotrophic phase. Indeed, recent studies on the symbiotic fungus Glomus intraradices showed that the effector SP7 contributes to the biotrophic status of symbiotic fungi in roots by counteracting the plant immune program (Kloppholz et al. 2011). When expressed in roots, SP7 leads to higher mycorrhization, whereas expression of SP7 in the necrotrophic fungus Magnaporthe oryzae attenuates root decay symptoms (Kloppholz et al. 2011). Recent development of the heterologous system to study effectors from biotrophic pathogens enabled the discovery and the functional analysis of a biotroph effector repertoire (Fabro et al. 2011), revealing effector candidates that enhance plant susceptibility to pathogens that are mainly localized to the plant cell nucleus (Caillaud et al. 2012). Functional analysis of such nuclear HaRxLs effectors will allow dissection of the components of the nuclear plant immune system targeted by biotrophic pathogens to promote long-term coexistence with their hosts.

\section{ACKNOWLEDGMENTS}

We thank the laboratories of Matthew Smoker (TSL, Norwich, UK), Jodie Pike (TSL, Norwich, UK), and Jim Beynon (University of Warwick, Warwick, UK) for Arabidopsis-stable transformants. We thank Lars Ostergaard's laboratory (JIC, Norwich, UK) for help with the description of the phenotype of the transgenic lines expressing HaRxLs and Mr. Andrew Davis for his help with the images. We also thank Dr. Maelle Jaouannet (INRA Sophia-Antipolis, France) for help with the manuscript. Finally, we thank The Gatsby Foundation. M.C.C. is supported by EMBO ALTF 614-2009 and Marie Curie FP7PEOPLE-2009-IEF long-term fellowships. L.W. is supported by a $F E B S$ long-term fellowship.

\section{REFERENCES}

Abramovitch RB, Kim YJ, Chen S, Dickman MB, Martin GB. 2003. Pseudomonas type III effector AvrPtoB induces plant disease susceptibility by inhibition of host programmed cell death. EMBO J 22: 60-69.

Alfano JR, Collmer A. 2004. Type III secretion system effector proteins: Double agents in bacterial disease and plant defense. Annu Rev Phytopathol 42: 385-414.

Allen RL, Bittner-Eddy PD, Grenville-Briggs LJ, Meitz JC, Rehmany AP, Rose LE, Beynon JL. 2004. Host-parasite coevolutionary conflict between Arabidopsis and downy mildew. Science 306: 1957-1960.

Armstrong MR, Whisson SC, Pritchard L, Bos JI, Venter E, Avrova AO, Rehmany AP, Bohme U, Brooks K, Cherevach I, et al. 2005. An ancestral oomycete locus contains late blight avirulence gene $A v r 3 a$, encoding a protein that is recognized in the host cytoplasm. Proc Natl Acad Sci 102: 7766-7771.

Bai X, Correa VR, Toruno TY, Ammar el D, Kamoun S, Hogenhout SA. 2009. AY-WB phytoplasma secretes a protein that targets plant cell nuclei. Mol Plant Microbe Interact 22: 18-30.

Bai S, Liu J, Chang C, Zhang L, Maekawa T, Wang Q, Xiao W, Liu Y, Chai J, Takken FL, et al. 2012. Structure-function analysis of barley NLR immune receptor MLA10 reveals its cell compartment specific activity in cell death and disease resistance. PLoS Pathog 8: e1002752.

Bailey K, Cevik V, Holton N, Byrne-Richardson J, Sohn KH, Coates M, Woods-Tor A, Aksoy HM, Hughes L, Baxter L, et al. 2011. Molecular cloning of ATR5(Emoy2) from Hyaloperonospora arabidopsidis, an avirulence determinant that triggers RPP5-mediated defense in Arabidopsis. Mol Plant Microbe Interact 24: 827-838.

Baxter L, Tripathy S, Ishaque N, Boot N, Cabral A, Kemen E, Thines M, Ah-Fong A, Anderson R, Badejoko W, et al. 2010. Signatures of adaptation to obligate biotrophy in the Hyaloperonospora arabidopsidis genome. Science 330: 15491551.

Bernoux M, Timmers T, Jauneau A, Briere C, de Wit PJ, Marco Y, Deslandes L. 2008. RD19, an Arabidopsis cysteine protease required for RRS1-R-mediated resistance, is relocalized to the nucleus by the Ralstonia solanacearum PopP2 effector. Plant Cell 20: 2252-2264.

Bhattacharjee S, Halane MK, Kim SH, Gassmann W. 2011. Pathogen effectors target Arabidopsis EDS1 and alter its interactions with immune regulators. Science 334: 1405-1408.

Birch PR, Rehmany AP, Pritchard L, Kamoun S, Beynon JL. 2006. Trafficking arms: Oomycete effectors enter host plant cells. Trends Microbiol 14: 8-11.

Birch PR, Armstrong M, Bos J, Boevink P, Gilroy EM, Taylor RM, Wawra S, Pritchard L, Conti L, Ewan R, et al. 2009. Towards understanding the virulence functions of RXLR effectors of the oomycete plant pathogen Phytophthora infestans. J Exp Bot 60: 1133-1140.

Bos JIB, Armstrong MR, Gilroy EM, Boevink PC, Hein I, Taylor RM, Tian ZD, Engelhardt S, Vetukuri RR, Harrower B, et al. 2010. Phytophthora infestans effector AVR3a is essential for virulence and manipulates plant immunity by stabilizing host E3 ligase CMPG1. Proc Natl Acad Sci 107: 99099914.

Boutemy LS, King SR, Win J, Hughes RK, Clarke TA, Blumenschein TM, Kamoun S, Banfield MJ. 2011. Structures of Phytophthora RXLR effector proteins: A conserved but adaptable fold underpins functional diversity. $J$ Biol Chem 286: 35834-35842.

Bouwmeester K, de Sain M, Weide R, Gouget A, Klamer S, Canut H, Govers F. 2011. The lectin receptor kinase LecRK-I.9 is a novel phytophthora resistance component and a potential host target for a RXLR effector. PLoS Pathog 7: e1001327.

Bozkurt TO, Schornack S, Win J, Shindo T, Ilyas M, Oliva R, Cano LM, Jones AM, Huitema E, van der Hoorn RA, Kamoun S. 2011. Phytophthora infestans effector AVRblb2 prevents secretion of a plant immune protease at the haustorial interface. Proc Natl Acad Sci 108: 20832-20837.

Brown JW, Shaw PJ, Shaw P, Marshall DF. 2005. Arabidopsis nucleolar protein database (AtNoPDB). Nucleic Acids Res 33: D633-D636.

Buttner D, Bonas U. 2002. Getting across: Bacterial type III effector proteins on their way to the plant cell. EMBO J 21: 5313-5322.

Caillaud MC, Dubreuil G, Quentin M, Perfus-Barbeoch L, Lecomte P, de Almeida Engler J, Abad P, Rosso MN, Favery B. 2008. Root-knot nematodes manipulate plant cell functions during a compatible interaction. J Plant Physiol 165: 104-113.

Caillaud M-C, Piquerez SJM, Fabro G, Steinbrenner J, Ishaque N, Beynon J, Jones JDG. 2012. Subcellular localization of the Hpa RxLR effector repertoire identifies a tonoplast- 
associated protein HaRxL17 that confers enhanced plant susceptibility. Plant J 69: 252-265.

Canonne J, Rivas S. 2012. Bacterial effectors target the plant cell nucleus to subvert host transcription. Plant Signal Behav 7: $217-221$.

Canonne J, Marino D, Jauneau A, Pouzet C, Briere C, Roby D, Rivas S. 2011. The Xanthomonas type III effector XopD targets the Arabidopsis transcription factor MYB30 to suppress plant defense. Plant Cell 23: 3498-3511.

Chou S, Krasileva KV, Holton JM, Steinbrenner AD, Alber T, Staskawicz BJ. 2011. Hyaloperonospora arabidopsidis ATR1 effector is a repeat protein with distributed recognition surfaces. Proc Natl Acad Sci 108: 13323-13328.

Deslandes L, Rivas S. 2012. The plant cell nucleus: A true arena for the fight between plants and pathogens. Plant Signal Behav 6: 42-48.

Dong S, Qutob D, Tedman-Jones J, Kuflu K, Wang Y, Tyler BM, Gijzen M. 2009. The Phytophthora sojae avirulence locus $A v r 3 c$ encodes a multi-copy RXLR effector with sequence polymorphisms among pathogen strains. PLoS One 4: e5556.

Dong S, Yin W, Kong G, Yang X, Qutob D, Chen Q, Kale SD, Sui Y, Zhang Z, Dou D, et al. 2011. Phytophthora sojae avirulence effector Avr3b is a secreted NADH and ADP-ribose pyrophosphorylase that modulates plant immunity. PLoS Pathog 7: e1002353.

Ellis J, Catanzariti A-M, Dodds P. 2006. The problem of how fungal and oomycete avirulence proteins enter plant cells. Trends Plant Sci 11: 61-63.

Fabro G, Steinbrenner J, Coates J, Ishaque M, Baxter N, Studholme L, Korner DJ, Allen E, Piquerez RL, Rougon-Cardoso SJA, et al. 2011. Multiple candidate effectors from the oomycete pathogen Hyaloperonospora arabidopsidis suppress host plant immunity. PLoS Pathog 7: e1002348.

Gilroy EM, Taylor RM, Hein I, Boevink P, Sadanandom A, Birch PR. 2011. CMPG1-dependent cell death follows perception of diverse pathogen elicitors at the host plasma membrane and is suppressed by Phytophthora infestans RXLR effector AVR3a. New Phytol 190: 653-666.

Goritschnig S, Krasileva KV, Dahlbeck D, Staskawicz BJ. 2011. Computational prediction and molecular characterization of an oomycete effector and the cognate Arabidopsis resistance gene. PLoS Genet 8: e1002502.

Guo Y, Ni J, Denver R, Wang X, Clark SE. 2011. Mechanisms of molecular mimicry of plant CLE peptide ligands by the parasitic nematode Globodera rostochiensis. Plant Physiol 157: 476-484.

Heidrich K, Wirthmueller L, Tasset C, Pouzet C, Deslandes L, Parker JE. 2011. Arabidopsis EDS1 connects pathogen effector recognition to cell compartment-specific immune responses. Science 334: 1401-1404.

Hewezi T, Howe PJ, Maier TR, Hussey RS, Mitchum MG, Davis EL, Baum TJ. 2010. Arabidopsis spermidine synthase is targeted by an effector protein of the cyst nematode Heterodera schachtii. Plant Physiol 152: 968-984.

Huang G, Dong R, Allen R, Davis EL, Baum TJ, Hussey RS. 2006a. A root-knot nematode secretory peptide functions as a ligand for a plant transcription factor. Mol Plant Microbe Interact 19: 463-470. doi: 10.1094/MPMI-19-0463.

Jiang RHY, Tripathy S, Govers F, Tyler BM. 2008. RXLR effector reservoir in two Phytophthora species is dominated by a single rapidly evolving superfamily with more than 700 members. Proc Natl Acad Sci 105: 4874-4879.

Jones JD, Dangl JL. 2006. The plant immune system. Nature 444: 323-329.

Kale SD, Gu B, Capelluto DG, Dou D, Feldman E, Rumore A, Arredondo FD, Hanlon R, Fudal I, Rouxel T, et al. 2010. External lipid PI3P mediates entry of eukaryotic pathogen effectors into plant and animal host cells. Cell 142: 284-295.

Kamoun S. 2007. Groovy times: Filamentous pathogen effectors revealed. Curr Opin Plant Biol 10: 358-365.

Kay S, Bonas U. 2009. How Xanthomonas type III effectors manipulate the host plant. Curr Opin Microbiol 12: 37-43.
Kay S, Hahn S, Marois E, Hause G, Bonas U. 2007. A bacterial effector acts as a plant transcription factor and induces a cell size regulator. Science 318: 648-651.

Kemen E, Jones JD. 2012. Obligate biotroph parasitism: Can we link genomes to lifestyles? Trends Plant Sci 17: 448-457.

Kemen E, Gardiner A, Schultz-Larsen T, Kemen AC, Balmuth AL, Robert-Seilaniantz A, Bailey K, Holub E, Studholme DJ, Maclean D, et al. 2011. Gene gain and loss during evolution of obligate parasitism in the white rust pathogen of Arabidopsis thaliana. PLoS Biol 9: e1001094.

Kloppholz S, Kuhn H, Requena N. 2011. A secreted fungal effector of Glomus intraradices promotes symbiotic biotrophy. Curr Biol 21: 1204-1209.

Koch E, Slusarenko A. 1990. Arabidopsis is susceptible to infection by a downy mildew fungus. Plant Cell 2: 437-445.

Korves TM, Bergelson J. 2003. A developmental response to pathogen infection in Arabidopsis. Plant Physiol 133: 339347.

Kwon SI, Kim SH, Bhattacharjee S, Noh JJ, Gassmann W. 2009. SRFR1, a suppressor of effector-triggered immunity, encodes a conserved tetratricopeptide repeat protein with similarity to transcriptional repressors. Plant J 57: 109-119.

Leonelli L, Pelton J, Schoeffler A, Dahlbeck D, Berger J, Wemmer DE, Staskawicz B. 2011. Structural elucidation and functional characterization of the Hyaloperonospora arabidopsidis effector protein ATR13. PLoS Pathog 7: e1002428.

MacLean AM, Sugio A, Makarova OV, Findlay KC, Grieve VM, Toth R, Nicolaisen M, Hogenhout SA. 2011. Phytoplasma effector SAP54 induces indeterminate leaf-like flower development in Arabidopsis plants. Plant Physiol 157: $831-841$.

Marois E, Van den Ackerveken G, Bonas U. 2002. The Xanthomonas type III effector protein AvrBs3 modulates plant gene expression and induces cell hypertrophy in the susceptible host. Mol Plant Microbe Interact 15: 637-646.

Mitchum MG, Wang X, Davis EL. 2008. Diverse and conserved roles of CLE peptides. Curr Opin Plant Biol 11: 75-81.

Morgan W, Kamoun S. 2007. RXLR effectors of plant pathogenic oomycetes. Curr Opin Microbiol 10: 332-338.

Mukhtar MS, Carvunis AR, Dreze M, Epple P, Steinbrenner J, Moore J, Tasan M, Galli M, Hao T, Nishimura MT, et al. 2011. Independently evolved virulence effectors converge onto hubs in a plant immune system network. Science 333: 596-601.

Nurnberger T, Brunner F. 2002. Innate immunity in plants and animals: Emerging parallels between the recognition of general elicitors and pathogen-associated molecular patterns. Curr Opin Plant Biol 5: 318-324.

Oh SK, Young C, Lee M, Oliva R, Bozkurt TO, Cano LM, Win J, Bos JI, Liu HY, van Damme M, et al. 2009. In planta expression screens of Phytophthora infestans RXLR effectors reveal diverse phenotypes, including activation of the Solanum bulbocastanum disease resistance protein Rpi-blb2. Plant Cell 21: 2928-2947.

Pedrotti S, Busa R, Compagnucci C, Sette C. 2011. The RNA recognition motif protein RBM11 is a novel tissue-specific splicing regulator. Nucleic Acids Res 40: 1021-1032.

Rehmany AP, Gordon A, Rose LE, Allen RL, Armstrong MR, Whisson SC, Kamoun S, Tyler BM, Birch PR, Beynon JL. 2005. Differential recognition of highly divergent downy mildew avirulence gene alleles by RPP1 resistance genes from two Arabidopsis lines. Plant Cell 17: 1839-1850.

Rentel MC, Leonelli L, Dahlbeck D, Zhao B, Staskawicz BJ. 2008. Recognition of the Hyaloperonospora parasitica effector ATR13 triggers resistance against oomycete, bacterial, and viral pathogens. Proc Natl Acad Sci 105: 10911096.

Rivas S. 2012. Nuclear dynamics during plant innate immunity. Plant Physiol 158: 87-94.

Schornack S, van Damme M, Bozkurt TO, Cano LM, Smoker M, Thines M, Gaulin E, Kamoun S, Huitema E. 2010. Ancient class of translocated oomycete effectors targets the host nucleus. Proc Natl Acad Sci 107: 17421-17426. 
Shan W, Cao M, Leung D, Tyler BM. 2004. The Avr1b locus of Phytophthora sojae encodes an elicitor and a regulator required for avirulence on soybean plants carrying resistance gene Rps1b. Mol Plant Microbe Interact 17: 394-403.

Slusarenko AJ, Schlaich NL. 2003. Downy mildew of Arabidopsis thaliana caused by Hyaloperonospora parasitica (formerly Peronospora parasitica). Mol Plant Pathol 4: 159170.

Sohn KH, Lei R, Nemri A, Jones JD. 2007. The downy mildew effector proteins ATR1 and ATR13 promote disease susceptibility in Arabidopsis thaliana. Plant Cell 19: $4077-$ 4090.

Sugio A, Kingdom HN, MacLean AM, Grieve VM, Hogenhout SA. 2011. Phytoplasma protein effector SAP11 enhances insect vector reproduction by manipulating plant development and defense hormone biosynthesis. Proc Natl Acad Sci 108: E1254-E1263.

Tian M, Win J, Song J, van der Hoorn R, van der Knaap E, Kamoun S. 2007. A Phytophthora infestans cystatin-like protein targets a novel tomato papain-like apoplastic protease. Plant Physiol 143: 364-377.

van Esse HP, Van't Klooster JW, Bolton MD, Yadeta KA, van Baarlen P, Boeren S, Vervoort J, de Wit PJ, Thomma BP. 2008. The Cladosporium fulvum virulence protein Avr2 inhibits host proteases required for basal defense. Plant Cell 20: 1948-1963.

Voegele RT, Mendgen KW. 2011. Nutrient uptake in rust fungi: How sweet is parasitic life? Euphytica 179: 41-55.
Wang X, Mitchum MG, Gao B, Li C, Diab H, Baum TJ, Hussey RS, Davis EL. 2005. A parasitism gene from a plant-parasitic nematode with function similar to CLAVATA3/ESR (CLE) of Arabidopsis thaliana. Mol Plant Pathol 6: 187-191.

Win J, Morgan W, Bos J, Krasileva KV, Cano LM, ChaparroGarcia A, Ammar R, Staskawicz BJ, Kamoun S. 2007. Adaptive evolution has targeted the C-terminal domain of the RXLR effectors of plant pathogenic oomycetes. Plant Cell 19: $2349-2369$.

Win J, Chaparro-Garcia A, Belhaj K, Saunders PGO, Yoshida K, Dong S, Schornack S, Zipfel C, Robatzek S, Hogenhout SA, et al. 2012. Effector biology of plant-associated organisms: Concepts and Perspectives. Cold Spring Harbor Symp Quant Biol 77: doi: 10.1101/sqb.2012.77.015933.

Wirthmueller L, Zhang Y, Jones JD, Parker JE. 2007. Nuclear accumulation of the Arabidopsis immune receptor RPS4 is necessary for triggering EDS1-dependent defense. Curr Biol 17: 2023-2029.

Yaeno T, Li H, Chaparro-Garcia A, Schornack S, Koshiba S, Watanabe S, Kigawa T, Kamoun S, Shirasu K. 2011. Phosphatidylinositol monophosphate-binding interface in the oomycete RXLR effector AVR3a is required for its stability in host cells to modulate plant immunity. Proc Natl Acad Sci 108: $14682-14687$.

Zhu S, Jeong RD, Venugopal SC, Lapchyk L, Navarre D, Kachroo A, Kachroo P. 2011. SAG101 forms a ternary complex with EDS1 and PAD4 and is required for resistance signaling against turnip crinkle virus. PLoS Pathog 7: e1002318. 


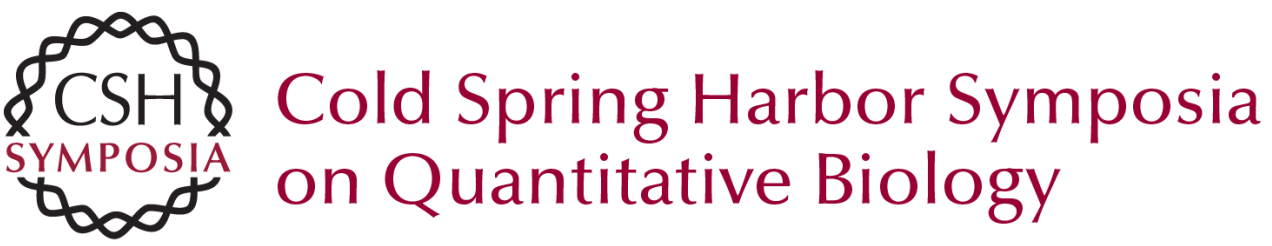

\section{Mechanisms of Nuclear Suppression of Host Immunity by Effectors from the Arabidopsis Downy Mildew Pathogen Hyaloperonospora arabidopsidis (Hpa)}

M.-C. Caillaud, L. Wirthmueller, G. Fabro, et al.

Cold Spring Harb Symp Quant Biol 2012 77: 285-293 originally published online December 4, 2012

Access the most recent version at doi:10.1101/sqb.2012.77.015115

$\begin{array}{ll}\text { References } & \text { This article cites } 72 \text { articles, } 33 \text { of which can be accessed free at: } \\ \text { http://symposium.cshlp.org/content/77/285.full.html\#ref-list-1 }\end{array}$

License

Email Alerting Receive free email alerts when new articles cite this article - sign up in

Service the box at the top right corner of the article or click here. 